\title{
Los paisajes agrarios de Galicia y el Arco Atlántico ${ }^{1}$
}

\author{
M. ${ }^{\text {a Pilar de Torres Luna* }}$
}

En 1972, y en circunstancias bien diferentes a las actuales, publiqué un artículo sobre la tipificación de los paisajes rurales de Galicia cuya ficha completa figura en la bibliografía del que ahora redacto. Al cabo, pues, de más de un cuarto de siglo (estoy escribiendo en junio de 1999) retomo el hilo con menos bisoñería que en aquella ocasión, con más experiencia investigadora sobre el tema y con la vivencia de haber sido testigo de la dinámica paisajística agraria de esta región española singular. No han sido ajenos a los cambios que a continuación expongo ni la simple evolución cronológica, ni el sucesivo acercamiento de España a Europa con su incorporación en 1986 a la Comunidad Europea, ni el «invento político» del Arco Atlántico comenzado a circular en 1989. Con el paso de Comunidad a Unión Europea y con la constitución de la Europa de las regiones, Galicia, forzosamente, se tenía que incorporar (se ha incorporado plenamente) a la fachada atlántica europea.

Efectivamente, la región gallega puede ser considerada, con toda propiedad, como un retazo de la fachada atlántica europea en el que su paisaje agrario tradicional está siendo modificado hasta tal punto que en un futuro no muy lejano se convertirá en otro inimaginable hace solamente 30 ó 40 años.

* Catedrático de Geografia. Universidad de Santiago de Compostela.

Con enorme gusto dedico este artículo al Prof. D. Jesús Garcia FERNANDEZ, geógrafo y maestro de geógrafos. Motivos de salud me han impedido añadirme, como hubiese sido mi deseo, al homenaje que recientemente le ha tributado la Universidad de Valladolid. 
Todos sabemos que los paisajes agrarios son una elaboración cultural por parte del hombre que, durante generaciones, ha actuado sobre el espacio natural sometiéndolo o utilizándolo de modo coyuntural y convirtiendo los terrazgos de cultivo en más o menos dinámicos según el momento histórico vivido. Galicia no ha sido ajena a los cambios aunque la evolución se ha realizado con lentitud o de modo imperceptible hasta el último cuarto de siglo. Pero la incorporación de hecho de España y sus regiones a Europa y de esta región al arco o eje atlántico han introducido a la Comunidad Autónoma en una dinámica imparable de mutaciones paisajísticas agrarias. Unas veces se trata de cambios cuantitativos materializados en la retracción de espacios; otras veces lo son cuantitativos, al haber cambiado las bases estructurales de esos espacios; en fin, la mayoría de los paisajes agrarios emergentes son consecuencia, a un tiempo, de la interacción espacial de cambios cuantitativos y cualitativos mezclados en muy variadas proporciones.

En las páginas siguientes trataré de presentar los paisajes agrarios de Galicia en una doble vertiente: por una parte, los derivados de una economía arcaizante, tradicional y poco evolucionada, que perviven mayoritariamente; por otra, los que me atreveré a llamar "nuevos», fruto de la nueva situación contextual europea, que se advierten tímidamente y que es de desear que, racionalizados y optimizados, sean el relevo de los actuales. No será, pues, tanto un artículo apoyado en estadísticas (que es preciso aportar en la medida conveniente) como en mi apreciación personal y en mis reflexiones realizadas sobre el terreno desde finales de la década de 1960 .

\section{GALICIA EN LA FACHADA ATLÁNTICA}

Resulta obvio decir, en los umbrales del siglo xxl, que Galicia forma parte de la fachada atlántica europea. Por su latitud entre los paralelos $41^{\circ} 48^{\prime}$ y $43^{\circ} 47^{\prime} \mathrm{N}$. queda comprendida en el ámbito que tradicionalmente se ha adscrito a las regiones de clima templado oceánico de latitudes medias y fachada occidental; este ámbito, con muchas matizaciones de detalle, se puede extender, lato sensu, desde el cabo portugués de San Vicente al noruego Norte, más allá del Círculo polar ártico.

Recientemente muchos autores han vuelto sobre esta cuestión de la "delimitación o emergencia de la noción de Europa atlántica" como ha escrito Flatrès, entre otros. Ajustando más, es posible decir que desde 1989 los políticos vienen hablando del "arco atlántico" reduciéndolo 
a las regiones marítimas de la fachada occidental de la Comunidad Europea.

En realidad se trata de una serie de espacios periféricos en el sentido de su alejamiento con relación al "corazón" de la Unión Europea, de finisterres altlánticos afectados desde el punto de vista geográfico humano por el predominio o destacado papel de las actividades derivadas de la agricultura y ganadería, por una defectuosa o incompleta industrialización (a veces por declive de la que existió), y por la falta de equipamiento o por subequipamiento en infraestructuras. Galicia encaja plenamente en este perfil.

Sin embargo, la personalidad del territorio gallego en la banda costera continental le viene de la combinación de sus caracteres topográficos y climáticos añadidos a un peculiar tipo de ocupación humana que ha construido en el transcurso de siglos una gran variedad de paisajes agrarios con la sintonia de fondo de su arcaismo no superado. Dependiendo precisamente de su dinamismo agrícola coyuntural Galicia se aleja o aproxima, depende, del contexto de las regiones del eje atlántico.

\section{CLIMA Y TOPOGRAFÍA, MODELADORES DE LOS PAISAJES AGRARIOS}

Galicia es la región atlántica española por excelencia en la que se registran del modo más acabado los caracteres climáticos oceánicos. Sin embargo, y esta es una gran originalidad, tanto las suaves temperaturas como las abundantes precipitaciones se degradan hacia el interior en sentido sureste dando un matiz de mediterranización que desaparece o está muy atenuado en toda la costa cantábrica española. Hay comarcas gallegas del interior que padecen fuerte aridez estival.

Este marco climático se ve profundamente modificado por la compartimentación topográfica. Los cerca de treinta mil kilómetros cuadrados de Galicia quedan alojados en su $51,6 \%$ en tierras comprendidas entre los 200-600 m. de altitud y constituyen realmente el armazón regional; el $16,9 \%$ de la extensión no llega a alcanzar los $200 \mathrm{~m}$. y el restante $31,5 \%$ se despliega por encima de los $600 \mathrm{~m}$. con una pequeña superficie que supera los $1.000 \mathrm{~m}$. Poco dirían estas cifras si no se alude a la estructura topográfica y a la silueta costera. Posee nuestra región más de mil kilómetros de costa (la mitad aproximadamente del litoral del arco atlántico) articulados en fantásticos entrantes y salientes en todo su litoral pero sobre todo en lo que conocemos como las rías bajas, coincidiendo con una gran templanza térmica a la vez que abundancia pluviométrica; este 


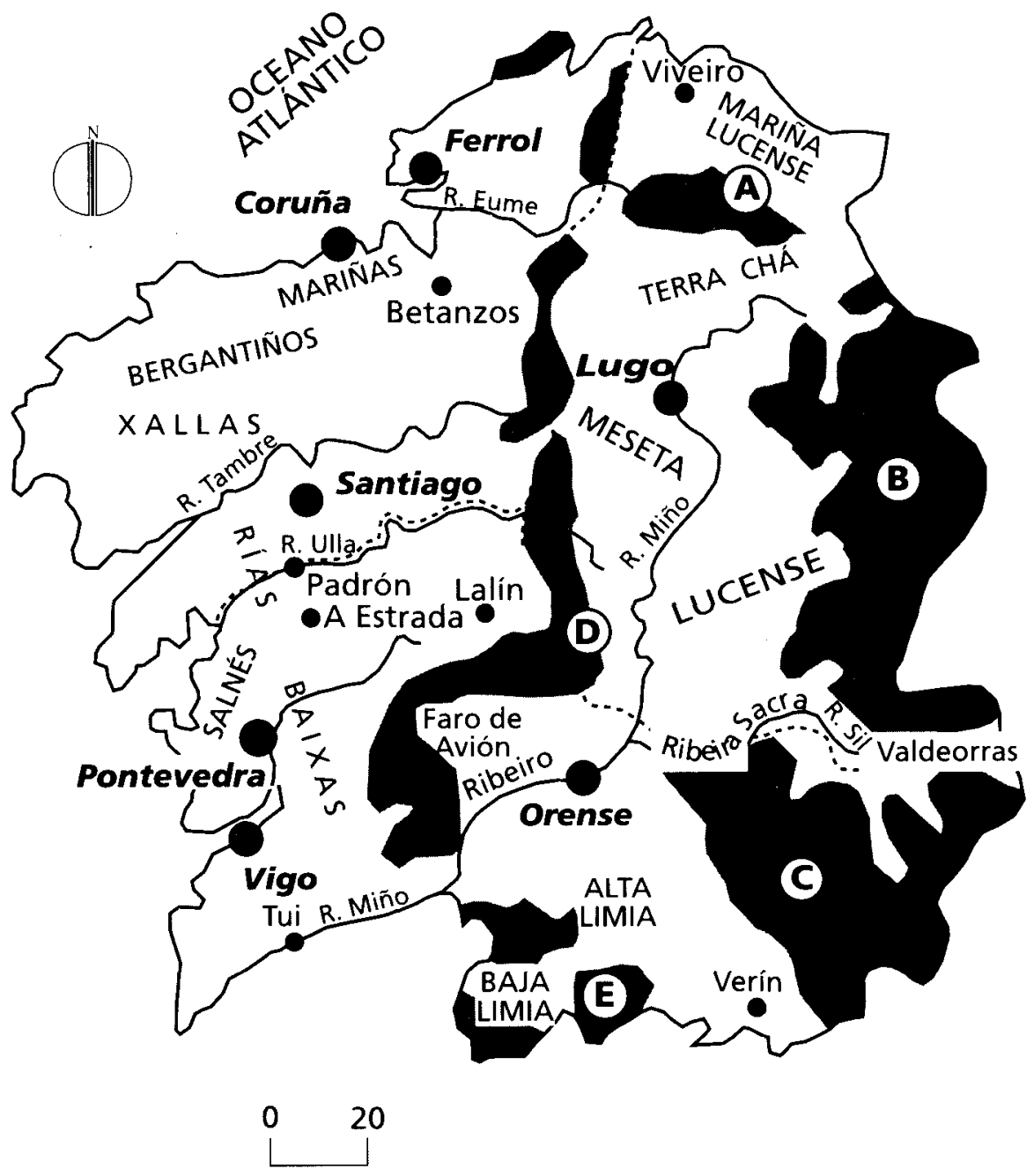

Galicia. Croquis de conjunto según A. Bouhier, 1998. (Traducción y adaptación de Torres Luna, 1999.) En rayado van las áreas montañosas: $A$, montañas septentrionales; $B$, montañas orientales; $C$, montañas surorientales; $D$, dorsal gallega; $E$, montañas meridionales. 
hecho propicia la posibilidad de una agricultura altamente rentable y ofrece paisajes agrarios evolucionados que ocupan los terrazgos inmediatos a la línea de costa y se amplían hacia el interior hasta alcanzar los $200 \mathrm{~m}$. de altitud, más o menos. Enmarcando las áreas costeras se eleva un cíngulo montañoso que con los nombres genéricos de sierras septentrionales y Dorsal meridiana, se completa por el este con las denominadas sierras orientales, por el sureste con el complejo de Manzaneda y por el sur con las sierras meridionales limítrofes con Portugal. Constituyen todas éstas, por sus paisajes agrarios, áreas de montaña donde los terrazgos cultivados son intermitentes y discontinuos, la población regresiva y el bosque y la landa los elementos más comunes. En su interior se alojan una serie de tierras más o menos planas y más o menos bajas como la meseta de Lugo, la Terra Cha, las depresiones de Monforte de Lemos, Sarria y Orense y los valles periféricos del Támega y el Limia. Se trata de comarcas donde es posible disponer de amplias extensiones para la agricultura hasta hace poco cerealícola y cada vez más pratense; se podría decir que aqui hay posibilidades para la intensificación agropecuaria y vitícola.

En suma, existe una gran variedad de paisajes agrarios basada más que en los elementos integrantes (que veremos que son muy reiterativos), en la combinación espacial de los mismos y en la discontinuidad añadida constantemente por la compartimentación topográfica en unidades de poca extensión.

\section{EL HOMBRE ARTÍFICE DE LOS PAISAJES AGRARIOS}

La humanización del territorio gallego es una constante en su historia que no ha podido minimizar ni la emigración de antaño ni el envejecimiento actual que en muchas ocasiones da lugar a abandonos de familias del rural para establecerse en las ciudades o en algunas grandes cabeceras comarcales. Es el hecho que todavía Galicia tiene a más de la mitad de sus habitantes residiendo en el rural y a más de la cuarta parte viviendo de la agricultura. Realidades que impactan directamente en sus paisajes agrarios.

Para dar una idea de la ocupación humana espacial en nuestra región se hace necesario aludir a los rasgos más sobresalientes de la misma. En una nota de urgencia podemos decir que la densidad de población es de 92,56 hab. $/ \mathrm{km}^{2}$, superior al promedio nacional, pero que este dato queda inexpresivo si no lo completamos resaltando que hay más de una entidad por cada kilómetro cuadrado. 
De manera rutinaria y con falta de precisión se ha incluido a Galicia demasiadas veces entre las áreas de habitat disperso de la fachada altántica, cuando se trata realmente no de una dispersión a secas sino de la existencia de una multitud de aldeas salpicando el espacio a distancias muy variables entre sí. Unas veces son, en su estructura nuclear, entidades $o$ aldeas concentradas, otras aglomeradas algo sueltas, otras laxas ... y existen también áreas de viviendas aisladas (las menos) que dan la verdadera imagen de la dispersión. Si seguimos combinando el número de habitantes con el de asentamientos, añadiré que nuestras casi 32.000 aldeas son núcleos pequeños: las de menos de 50 personas se acercan al $70 \%$ de la totalidad y si contamos las de menos de 200 el porcentaje supera el 95. La aldea, pues, es el segundo y más importante escalón en la jerarquía de los asentamientos y es la que posee más representación e imprime más fuerza al paisaje, el paisaje humanizado de que hablaba Otero Pedrayo. Niemeier, por su parte, aseveró con gran acierto que «la aldea cerrada aparece como la más antigua forma fundamental de las instalaciones humanas en Galicia». Pero las aldeas no salpican caprichosamente el terreno sino que se articulan o asocian en conjuntos más o menos numerosos formando asi las parroquias, verdaderas células sociales del mundo rural gallego, con una enorme carga humana y funcional, ésta en trance de desarticulación. Los límites de las parroquias rurales son nítidos y operativos aunque no estén, hasta el momento, reconocidos jurídicamente. Hay cerca de 4.000 parroquias, lo que supone una docena por municipio (en Galicia hay en este momento 315 términos municipales) y una superficie media de $7,7 \mathrm{Km}^{2}$ de extensión por parroquia.

Más que cifras, ya lo he dicho, prefiero el comentario espacial. Y lo hago sobre la cartografía puntual de las parroquias rurales que realicé hace más de un cuarto de siglo, publiqué por quinta vez en 1994 y ahora sale aquí retocada y puesta al día en junio de 1999. En este mapa, se observa una gran concentración de parroquias (generalmente con muchas aldeas cada una, que a esta escala son irrepresentables) en: la depresión de Orense, donde abundan los suelos propicios para el cultivo de la vid; en la cabecera del valle del río Ulla, área favorable para la ocupación pratense y ganadera; en la depresión de Sarria y centro de la meseta de Lugo, que son tierras tradicionalmente cerealeras y ganaderas; en el Golfo Artabro como en las Rías Bajas, aprovechando la benignidad climática y la proximidad a ciudades a las que han abastecido desde siempre de productos agropecuarios; en el valle medio del Ulla y en el Bajo Miño, que son comarcas de proverbial fertilidad, etc. 


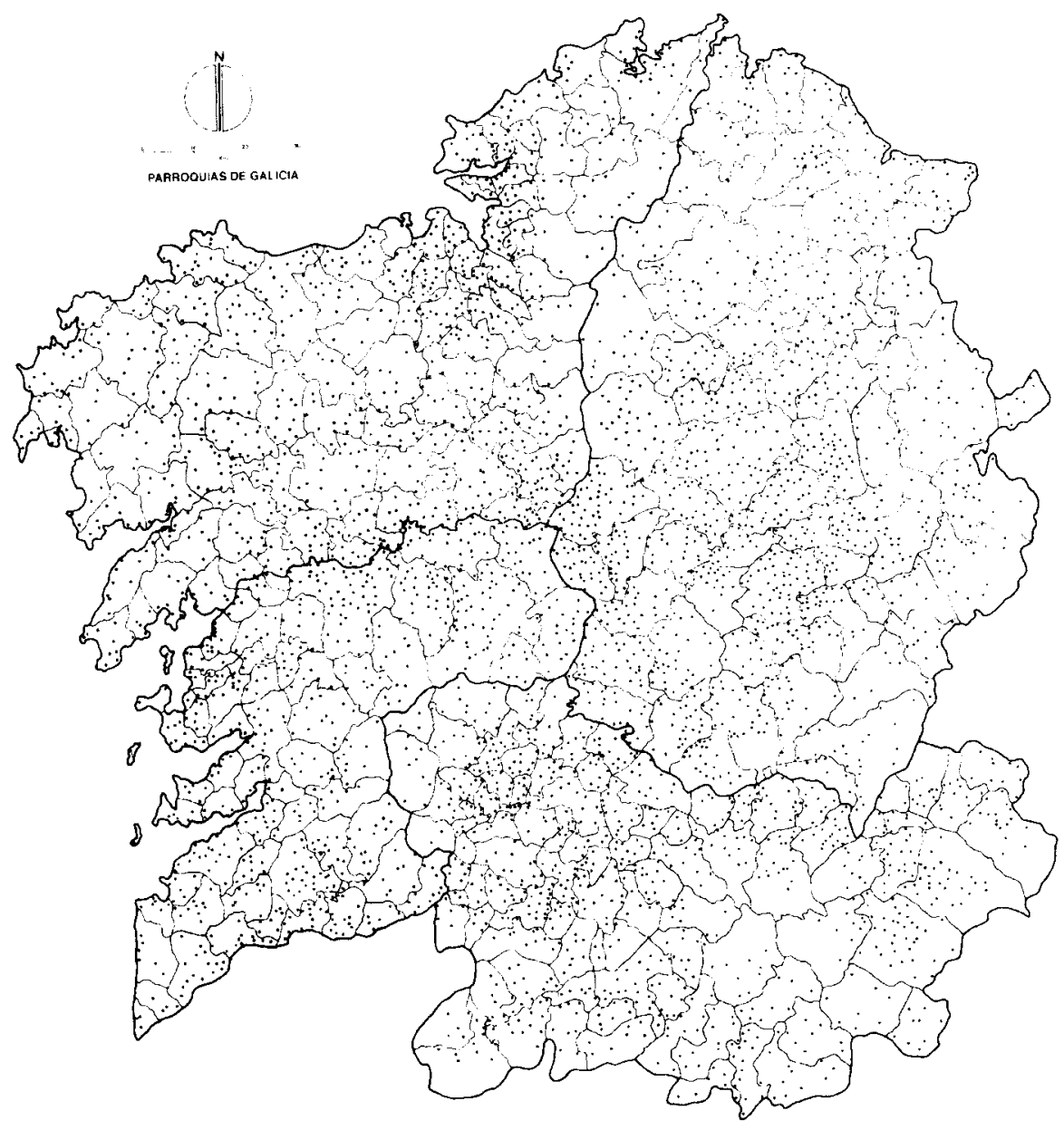

Los municipios de Galicia y sus parroquias en 1999. (Fuente: Investigaciones personales. Elaboración propia arreglada y puesta al día desde la primera publicación en 1976.) 
Cada aldea dispone de un terrazgo de cultivo circundante en el que las familias campesinas establecen sus rotaciones alternando libremente los ciclos vegetativos, con lo cual las combinaciones paisajísticas, reiteradas y entremezcladas, ofrecen un variopinto mosaico.

\section{BASES ESTRUCTURALES VISIBLES DE LOS PAISAJES AGRARIOS}

Sin descender en excesivo al detalle, es obligado aludir al peso histórico del régimen de propiedad de la tierra en Galicia; enseguida veremos que ha supuesto un importante hándicap en cuanto a la transformación y modernización de los paisajes agrarios. El foro, contrato que secularmente ha regulado el uso y disfrute de las tierras por el campesinado, ha pervivido, de iure, hasta 1926 en que una ley (la conocida como Ley Primo de Rivera) redimió la situación foral permitiendo a los agricultores el acceso a la plena propiedad. El que este hecho se produjera hace algo más de 70 años y que, de facto, la situación previa se prolongara en numerosos espacios hasta nuestros días, ha repercutido y sigue repercutiendo en el proceso de modernización de los paisajes y explica la pervivencia de los sistemas agrarios tradicionales. La compartimentación secular de la tierra, además, ha ido desembocando paulatinamente en la formación de un gran número de explotaciones agrarias, por lo general de pequeño tamaño y múltiples parcelas destinadas a cultivos para autoconsumo familiar, hecho que ha justificado, a su vez, el policultivo. Policultivo, por otra parte, consustancial con las manifestaciones de nuestro paisaje agrario tradicional. Explotaciones, parcelas, campesinos y cultivos: he aqui las bases.

Hace cerca de 40 años (primer Censo agrario de 1962) habia en Galicia 433.969 explotaciones agrarias, particularmente abundantes en la Galicia occidental ya que las provincias de Coruña y Pontevedra detentaban el $56 \%$ de ellas. Un cuarto de siglo después (último Censo agrario de 1989) su número había descendido algo pero la tendencia en la localización continuaba: 359.157 explotaciones (74.539 menos que en 1962) ubicadas en un $55 \%$ en territorios de Coruña y Pontevedra. El promedio de unidades de producción por municipio es, en ambas fechas, bastante homogéneo con cifras de mil por término y excepciones por superación de este número asociadas a tierras con importantes bolsas de población campesina como es el caso de Villalba, Fonsagrada, Silleda, Lalín... en la Galicia interior y montañosa. El siguiente cuadro estadístico es una buena aproximación a la realidad: 


\begin{tabular}{lcrrr}
\hline Provincias/GALICIA & 1962 & 1972 & 1982 & 1989 \\
\hline Coruña & 4,40 & 6,91 & 5,23 & 5,15 \\
Lugo & 8,97 & 11,63 & 9,84 & 10,46 \\
Orense & 6,90 & 8,75 & 7,28 & 6,70 \\
Pontevedra & 3,08 & 4,23 & 3,54 & 3,41 \\
GALICIA & 5,58 & 7,61 & 6,22 & 6,17 \\
\hline
\end{tabular}

Tamaño medio, en hectáreas, de las explotaciones agrarias. (Fuente: Censos agrarios de España. Elaboración propia.)

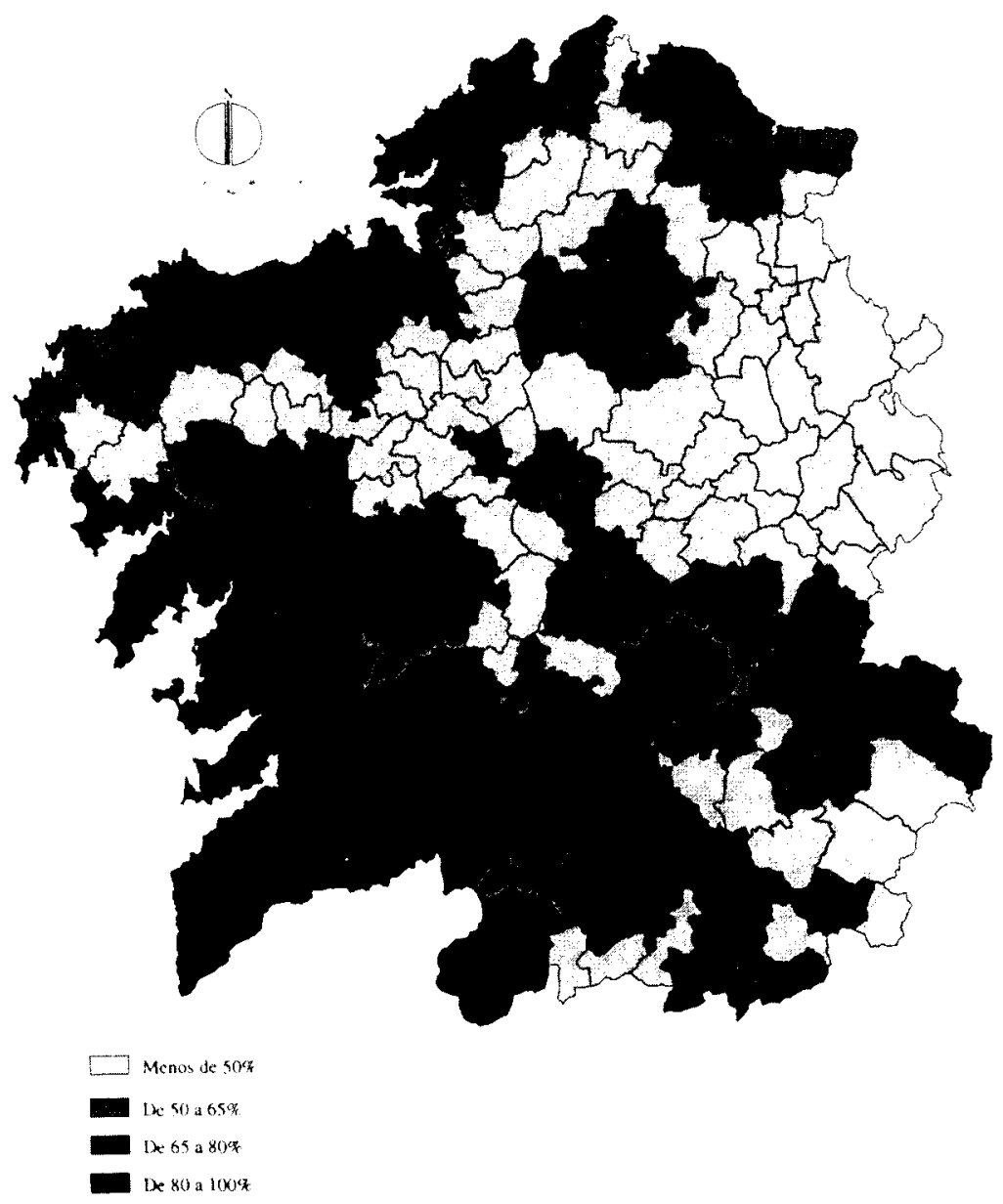

Galicia. Porcentaje de las explotaciones agrarias de hasta 5 Has. con relación al total de explotaciones en cada municipio. (Fuentes: Censo Agrario de 1989 y Galicia en cifras, 1997. 
Por lo que se refiere al tamaño, cuestión que interesa más ahora, destaca inmediatamente otra caracteristica del campo gallego que es la proliferación de pequeñas explotaciones agrarias. Entre las fechas de referencia se observa un ligero aumento de la extensión media, que ha pasado de 5,58 a 6,17 Has.; esta pequeña dimensión se justifica, de un lado, por la presión demográfica (en declive) existente en el medio rural, y de otro, por la elevada fertilidad de la tierra en la mayor parte de las comarcas. Sin embargo, la situación real es todavía más negativa para el espacio agrario ya que las estadísticas contabilizan en la explotación tanto las tierras de uso agrícola (cultivos y prados) como las destinadas a pastos y a terrenos forestales. Por provincias se matiza el tamaño medio de las unidades de producción dando menos extensión las occidentales (Pontevedra, 3,08 y 3,41 Has.; Coruña, 4,40 y 5,15 Has.) que las orientales (Orense 6,90 y 6,70 Has.; Lugo 8,97 y 10,46 Has.). Lógicamente el tamaño disminuye (explotaciones de menos de 3 Has.) en los espacios de agricultura muy intensiva, escasa altitud y próximos a los grandes centros de consumo como son las Rías Bajas, Mariñas coruñesas y comarca vitícola del Ribeiro, y aumenta (explotaciones de más de $10 \mathrm{Has}$.) en las áreas de montaña como son las Sierras orientales y surorientales y la Dorsal meridiana.

El grado de parcelación termina de perfilar las explotaciones. Hay en Galicia más de cinco millones de parcelas, que hace veinticinco años eran más de siete. La concentración parcelaria, comenzada en esta región en 1954, ha remediado algo la situación de extremo minifundio. Pero en el casi medio siglo de actuaciones todavía faltan 79 municipios (más de un tercio de la totalidad) en los que, por diversas razones, no ha tenido lugar esta mejoría del campo que tanto ha incidido y está incidiendo en la transformación de los paisajes agrarios. $Y$ asi podemos seguir diciendo que cada explotación cuenta, aproximadamente, con 15 parcelas por lo general distantes entre sí y con extensiones tan diminutas que en muchas ocasiones no alcanzan ni de lejos la media hectárea. El mapa adjunto evidencia las áreas afectadas por la concentración parcelaria hasta 1996 (fecha de la última actualización) y subraya los espacios de agricultura más intensiva, de productividad más elevada y de mayores densidades de población rural.

Los empresarios o jefes de explotación que detentan, gestionan y rentabilizan las unidades de producción acabadas de caracterizar constituyen, en el contexto de la Comunidad Autónoma, un grupo muy numeroso, con poca formación en general y con demasiada edad. Numeroso porque los que tienen por ocupación principal la actividad agraria suponen más de la mitad de los de Galicia. Sin cualificar porque la mayoría se ha dedicado a la agricultura para sobrevivir o por inercia, sin dar importancia a la for- 


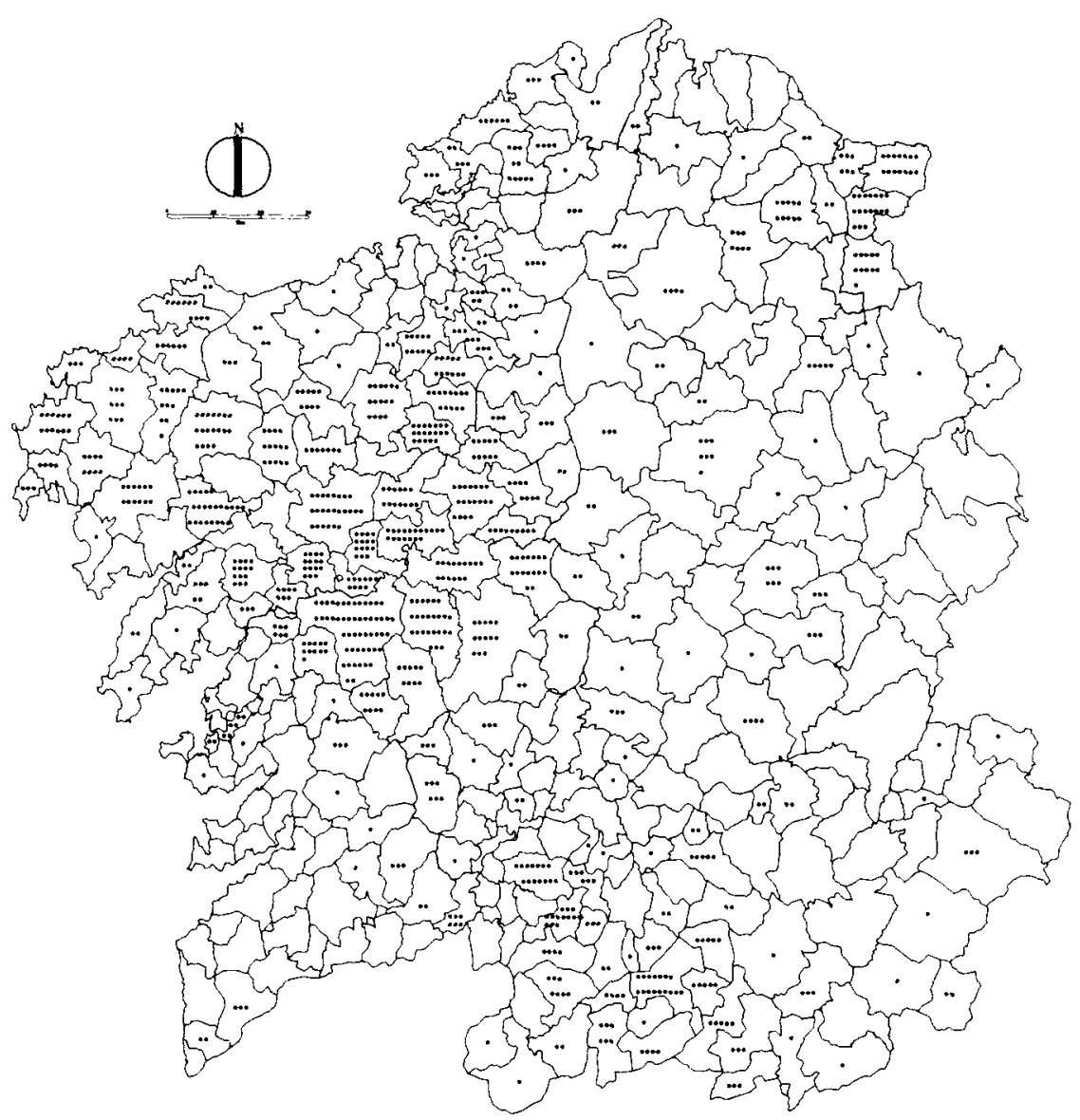

Galicia. Número de intenenciones de la concentración parcelaria por municipio hasta 1996. Los que quedan en blanco no han sido tocados por la concentración. (Fuente: Conselleria de Agricultura, Gandería e Politica Agroalimentaria de la Xunta de Galicia. Elaboración propia.)

mación. La avanzada edad se debe a una serie de circunstancias como la pura evolución cronológica, la emigración en las edades intermedias o la adscripción al campo hasta los 70 años de muchos que en su momento no cotizaron para poderse jubilar antes. El caso es que los propietarios de 65 años de edad en adelante constituyen un abultado grupo de más del $40 \%$ y que en sus parcelas predomina el policultivo de autoconsumo; de cualquier modo, una proporción tan elevada de empresarios muy mayores es sintoma de la decadencia y escasa capacidad de transformación de una buena parte del campo gallego. 


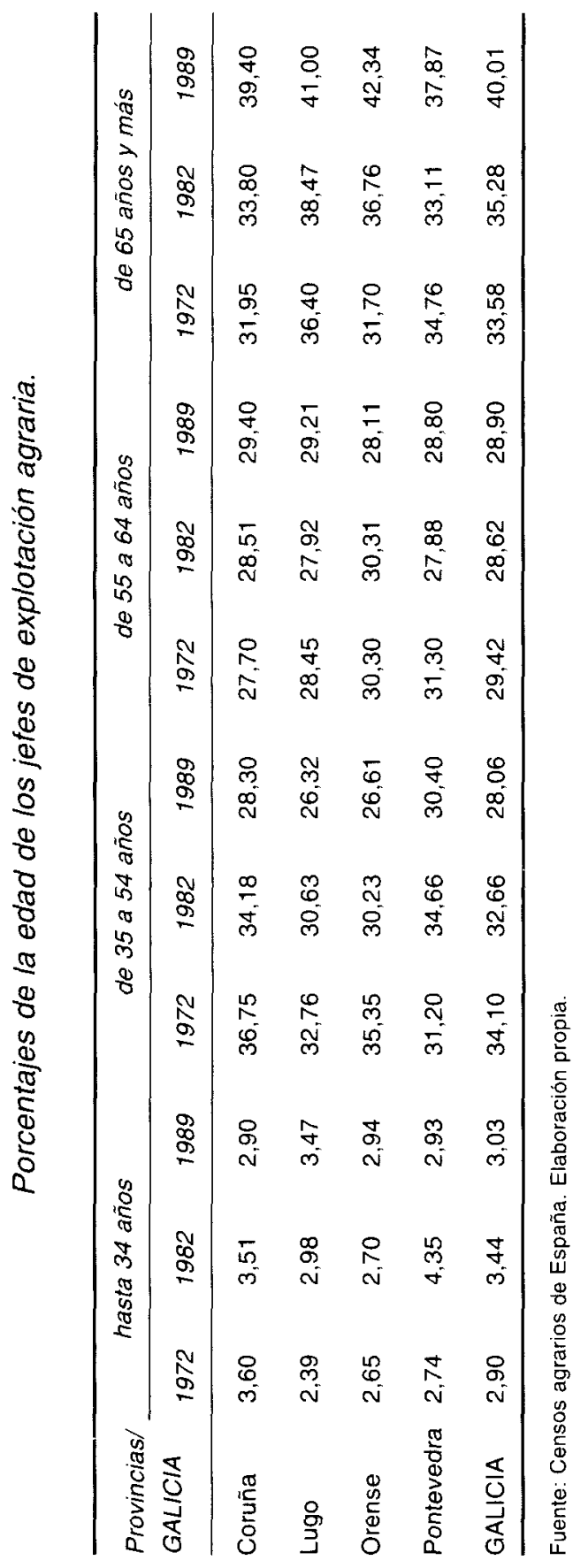


En otro rápido comentario de cifras se constata que en la práctica totalidad de Galicia los jefes de explotación de menos de 35 años suponen un porcentaje realmente bajo. Hay comarcas en que la fuerte emigración ha hecho testimonial la existencia de los que podemos denominar jóvenes agricultores; es de comentar, no obstante, que el $2,90 \%$ que suponian estos empresarios agrícolas hace un cuarto de siglo se ha elevado a algo más del $3 \%$ en la actualidad, lo cual puede explicarse bien porque se trate de personas con mentalidad empresarial aplicada a la agricultura, bien por la incorporación a las tareas del campo de jóvenes obreros industriales víctimas de la crisis del sector secundario, bien por la implantación de cooperativas de comercialización agraria en las que trabaja generalmente personal de 20 a 30 años de edad. En cualquier caso se trata de una puerta abierta a la esperanza de cara a un futuro positivo.

Los elementos de los paisajes agrarios que más fácil y rápidamente cambian son los cultivos. Acabamos de apreciar que todo lo referente a las estructuras se está modificando con mayor lentitud y dificultad. La ocupación general del espacio agrario gallego en porcentajes referidos a 1997 (es la estadística más reciente que existe) ofrece la primera aproximación: el $30,88 \%$ de las tierras están dedicadas tanto a los cultivos (en sentido estricto y en su mayoría herbáceos) como a los genéricamente denominados prados y pastos. El restante $69,12 \%$ es terreno mayoritariamente forestal.

Si fijamos la atención en el volumen de producción de los principales cultivos observaremos que van a la cabeza destacadísimas las praderas polifitas o artificiales, con casi 4,5 millones de toneladas, unos rendimientos sorprendentes que ponen a Galicia a la cabeza de la producción española. La superficie dedicada a este ocupante aumenta con gran rapidez pues de 22.000 Has. en los años sesenta se ha pasado a 133.400 en 1994. Se trata, en suma, de un aprovechamiento en fuerte expansión reciente por todo el territorio y en perfecta simbiosis con el creciente desarrollo ganadero de Galicia. Hecho que origina un gran impacto en el paisaje agrario. El maíz forrajero va en segundo lugar tanto por la producción de 2,4 millones de toneladas como por la superficie dedicada (62.000 Has), que también va en aumento. Esta planta es, de modo emblemático, el cultivo tradicional gallego que ha rotado en el ciclo agricola anual con los cereales. Se localiza sobre todo en la Galicia occidental, hasta los $200 \mathrm{~m}$. de altitud, su óptimo según algunos autores; las variedades hibridas, cada vez más dominantes por su destino ganadero, permiten el cultivo del maíz en tierras más elevadas. Este cultivo ha dejado de ser la base imprescindible de la alimentación humana. La patata, difundida aqui como el maíz en el siglo XVIII, ha sido con él uno de los cultivos "revolucionarios" del campo gallego; en principio se destinaba a consumo animal pero poco a poco se ha converti- 
do en alimento humano y ha hecho de la región gallega una despensa de patatas que por su producción va a la cabeza de todas las Autonomías españolas. La vid ocupa alrededor de 28.000 Has. y con fases alternantes de retroceso y aumento se mantiene gracias a la concesión de denominaciones de origen del vino elaborado que permiten su comercialización. Pero lo interesante ahora es decir que su localización espacial conforma paisajes agrarios muy peculiares por ser cultivo que define y delimita comarcas enteras como el Ribeiro, Valdeorras y Monterrey. Los cultivos protegidos, de ciclo manipulado o de invernadero (que con todos estos nombres los conocemos) se perfilan cada vez más como expresión de las nuevas tendencias surgidas en nuestra agricultura, aunque hasta el momento son puntuales pero imprimen huellas muy visibles y muy llamativas en los paisajes y desde luego establecen contrastes entre las áreas más dinámicas y abiertas a la modernización y las que todavía permanecen más apegadas a lo tradicional. Están representados tanto por hortalizas como por flores y otras plantas ornamentales. Sólo un ejemplo para demostrar su pujanza: en 1973 se dedicaban en Galicia 200 áreas de terreno a claveles que en 1994 habian pasado a 157 Has. He obviado la cita expresa a los cereales tradicionales (trigo, centeno, cebada, avena) porque de ser los cultivos para grano más cosechados desde antiguo han pasado a tener poca importancia tanto en la extensión que se le dedica como en los rendimientos que se obtienen, y su papel en los paisajes agrarios está cada vez más difuminado a escala regional. Podría ampliar la cita de plantas cultivadas pues la paleta gallega es rica pero ya están mencionadas las que se relacionan más directamente con la dinámica de los paisajes agrarios.

\section{BASES ESTRUCTURALES INVISIBLES DE LOS PAISAJES AGRARIOS}

Si los aspectos materiales repasados en el epígrafe anterior son de importancia capital en la valoración y establecimiento de tipologías de los paisajes agrarios de Galicia, tradicionales o renovados, no lo son menos los derivados del comportamiento secular de nuestra sociedad rural. Ahora utilizo la palabra "invisible" en referencia a bases estructurales porque el panorama que observamos en el campo gallego es consecuencia directa de la idiosincrasia, mentalidad y psicología de los habitantes de cada etapa histórica.

El modelo agrario tradicional, tan exclusivo y pervivente hasta fechas recientes, tenía unas características culturales que propiciaban capacidades sensiblemente diferentes a las del modelo que está irrumpiendo en la época actual. Pero ese sistema está, cuando menos, en fase de intensa crisis o de- 
rrumbándose; nos encontramos ante un proceso de cambio irreversible. Sin embargo, es un hecho que la población rural se ha caracterizado desde siempre por su resistencia a aceptar cualquier modificación: el peso de prácticas agrícolas seculares es muy difícil de relevar en poco tiempo. El problema del minifundio parcelario (algo paliado por los efectos de la concentración de tierras), el pequeño tamaño de las explotaciones y la edad de sus dueños es un hecho perceptible en el paisaje. Se diría que esto es poca cosa comparado con las pautas de comportamiento de la sociedad rural: atávica jerarquía de valores y sensibilidades, dejación, inercia, falta de iniciativa, influencias o pervivencias de servidumbres comunales o colectivas como el cultivo obligatorio en hojas o manos, del que hay huellas en muchas parroquias cuyos ancianos campesinos confiesan haber practicado hasta hace 30 ó 40 años. También las ayudas mutuas en los momentos críticos del ciclo de los cultivos sobre todo en la recolección, la reparación de cercas de piedra o seto vivo lindantes con caminos vecinales..., en definitiva, carencia de profesionalización y escasa vocación comercial.

Nuestra integración en la Unión Europea ha contribuido de un lado, a acentuar la crisis del modelo agrario tradicional, y de otro, a la necesidad de configurar un nuevo modelo que los agricultores no pueden elaborar aisladamente. En el momento histórico presente, y según todos los indicadores agrarios, es más lo que está llamado a cambiar que a permanecer y ese hecho es, en verdad, lo que caracteriza el final de una época y el comienzo de otra diferente.

La clave del cambio reside en que los paisanos necesitan adquirir una mentalidad propia de la época en que vivimos y una preparación acorde con esa cultura. Han de cambiar las formas de pensar y de comportarse de manera que cada jefe de explotación se convierta en un empresario agrícola; a partir de ahí tendrán lugar, seguro, mutaciones en los paisajes agrarios, pero mutaciones que sean positivas y no destructoras $u$ olvidadizas de las tierras que van quedando abandonadas.

Con estas más o menos hilvanadas ideas llego a la conclusión de que en Galicia encontramos paisajes agrarios con fuerte pervivencia de lo tradicional, interesantes apuntes de paisajes nuevos o emergentes y, como en el resto de la fachada atlántica europea, paisajes de abandono agrícola.

\section{PAISAJES AGRARIOS TRADICIONALES}

Son los más representados desde el punto de vista espacial ya que se les encuentra por toda Galicia. Constituyen el telón de fondo del agro gallego y a 
partir de ellos se han realizado, o se están realizando, las transformaciones. Sus elementos caracterizadores más visibles sobre el terreno son:

- Policultivo muy acentuado en función de la autosubsistencia del campesinado: cereales, maiz, patata, prados, cultivos de huerta (en las proximidades de las viviendas) y algunos frutales se mezclan sobre un parcelario atomizado. En áreas puntuales había monocultivo de vid (Miño lucense, Ribeiro, valles del Sil y del Bibey...).

- Apenas ha habido concentración parcelaria.

- El espacio forestal y la landa también forman parte de estos paisajes al ser ambos usos del suelo complemento de la agricultura en la economía tradicional.

- Existen terrazgos, ya muy pocos, sobre lo que se practican rotaciones de cultivos tan primitivas que mezclan el cereal o el prado con el arbolado y la landa.

- Se practica agricultura de rozas sobre la landa.

- Ausencia de mecanización, por lo que el trabajo de la tierra era realizado por el hombre con sus animales, lo cual evidencia la secular simbiosis entre la agricultura, la ganadería y el uso del monte.

- En numerosas ocasiones es paisaje de bocage, agras o campos cerrados en general, como consecuencia del modo de apropiación de la tierra y del tipo de explotación con base ganadera aunque poco desarrollada. montaña.

- Son paisajes muy perviventes en la Galicia interior y en las áreas de

Hacia los años 1970 se puede datar el inicio de una lenta transformación de los rasgos arcaizantes en función, sobre todo, de la intensificación y racionalización ganadera. $Y$ así:

- Las parcelas aumentan de tamaño con el avance de la concentración parcelaria.

- La superficie pratense se intensifica en consonancia con el auge ganadero (sobre todo del vacuno para leche), a expensas de los cereales panificables tradicionales y de otras plantas cultivadas para consumo humano.

- Incluso se realizan roturaciones de matorral para ampliar los espacios dedicados a praderas artificiales. Galicia se va así convirtiendo en un gran tapiz verde salpicado de grupos de vacas de raza frisona o pardo-alpina pastando al aire libre.

- Aparecen algunos cultivos con clara finalidad comercial: kiwi, plantaciones de frutales, fresas en invernadero... muy localizados en puntos 
del occidente de Galicia y sobre todo en áreas próximas a las ciudades como Vigo, Coruña o Pontevedra.

- Buena parte del interior regional, y sobre todo las áreas de montaña, permanecen como espacios rurales frágiles.

\section{PAISAJES AGRARIOS NUEVOS}

En la década de 1980 la consolidación de paisajes agrarios nuevos en Galicia es un hecho. Sin embargo, no ocupan más que pequeñas áreas salpicando el rural, que todavia no ha perdido sus rasgos de arcaísmo. Estas imágenes pueden ser:

- Resultado de la modernización ganadera que ha impactado sobre la superficie pratense; en estos casos tanto los prados artificiales como el maíz forrajero han desbancado prácticamente a los demás cultivos.

- Resultado de la implantación de especies de alta rentabilidad sobre amplios terrazgos: cultivos de primicias o protegidos del Golfo Artabro, valle del Salnés, Rías Bajas en general, Bajo Miño, etc.; plantaciones de frutales o de kiwi en las mismas comarcas y excepcionalmente (pero con buenos resultados) en puntos del interior como la depresión de Monforte de Lemos en la provincia de Lugo, con sus invernaderos y plantaciones de frutales, o la comarca de la Arnoia en la de Orense, también con frutales.

Se deben mencionar aquí los terrazgos vitícolas, en particular los que no han evolucionado hacia el abandono o la disminución de sus extensiones. Aunque existen desde antiguo, la conexión de muchos de esos espacios con la política comunitaria europea ha supuesto un cambio en los tipos de viníferas para poderse incorporar a los circuitos comerciales.

\section{PAISAJES AGRARIOS EXCEPCIONALES EN GALICIA}

Los denomino así, prescindiendo de su cronología, porque los ejemplos que voy a comentar son el resultado de las actuaciones que tuvo (entre más o menos 1956 y el final de la década de 1960) el entonces denominado Instituto Nacional de Colonización. Por supuesto las técnicas de mantenimiento de estos espacios se han modernizado mucho desde los inicios de su funcionamiento.

En el centro de la varias veces aludida Terra Cha (municipios de Castro de Rey y Cospeito) los paisajes nuevos creados en la llanura de Castro de Rey son muy llamativos por la imagen de prosperidad que ofrecen sus 
grandes y bien cuidadas parcelas dedicadas a praderas artificiales para alimento de las muchas cabezas de vacuno lechero que integran sus numerosas granjas. Muy cerca de aquí se llevó a cabo la desecación de la laguna de Cospeito y en los espacios recién conquistados se prepararon terrazgos orientados fundamentalmente a la explotación ganadera vacuna y menos al cultivo de frutales. Constituyó, en suma, la actuación concreta sobre un espacio natural que permitió el incremento de la superficie agrícola. En estas dos actuaciones se hizo necesaria la movilización de campesinos para habitar los nuevos asentamientos creados para albergar a los colonos.

En el sur de la provincia de Orense, municipio de Xinzo de Limia, el impacto colonizador también tuvo lugar sobre un espacio natural y su ecosistema. La desecación de la laguna de Antela posibilitó igualmente la ampliación de los terrazgos de cultivo aprovechando la topografía plana. Sobre ella se ha establecido un parcelario en damero y una red caminera cuadriculada pero conservando la localización originaria de las viejas aldeas en el contacto entre el espacio desecado y el previamente existente. Aquí no ha habido creación de nuevos asentamientos. La superficie conquistada a la laguna se dedica al cultivo masivo de la patata aunque van proliferando las granjas ganaderas cooperativizadas.

Quizá encajen en este apartado los paisajes agrurbanos o rururbanos que se están conformando en el anillo circundante de las grandes ciudades, donde por el momento se funde lo rural-agrario con lo urbano a base de las construcciones de viviendas aisladas de primera residencia o de urbanizaciones compactas que invaden el espacio en el que todavía perviven muchas casas de agricultores con su huerta y parcelas de labor. El ejemplo del sureste del municipio de Santiago de Compostela es emblemático en este sentido.

\section{PAISAJES DE ABANDONO AGRICOLA}

Aunque falta en Galicia un estudio sistemático y detallado de este tema, mis investigaciones de equipo (en parte publicadas) permiten decir que nos encontramos asistiendo a un lento proceso de paso de un mundo rural caracterizado por una fuerte presión demográfica y agrícola sobre las tierras a una situación de abandono creciente, tanto de terrenos difíciles como de algunos fértiles. Hay pocos jóvenes agricultores, ya lo he dicho, y como en muchos casos no se producirá el relevo generacional al frente de las explotaciones, el retroceso de los terrazgos agrícolas proseguirá y se acentuará. También contribuye al fenómeno el envejecimiento de muchos campesinos, también lo he dicho, y el que bastantes se ocupen en actividades 
extraagricolas aunque sea a tiempo parcial. Posiblemente la aplicación de una adecuada política agraria al respecto, en todas las regiones de la fachada atlántica europea, llevaría a reconducir esta triste realidad.

La localización de los espacios abandonados es muy aleatoria porque obedece a factores muy variados y difíciles de conectar. En principio, es lógico que el hecho afecte a tierras del interior a causa de la fuerte pendiente que no permite la mecanización (abandonos espectaculares de los viñedos del Bibey), pero también está muy generalizado en comarcas de acentuada emigración; en estas últimas comarcas se recurre a veces a la plantación de coníferas sobre los campos que eran de cereal y otras veces se descuidan, puede que a la espera de mejor ocasión para volver a ponerlas en cultivo.

\section{BIBLIOGRAFIA}

Anuario de estatistica agraria. Xunta de Galicia, Varias fechas de las que la última ha sido 1997.

Arc Atlantique. Monográfico de la Rev. Norois. N. ${ }^{\circ} 157$, janviers-mars 1993, pág. 192.

Bertrand, J.R.: A poboación de Galicia. Estudios xeográficos. Universidade de Santiago de Compostela, 1992, pág. 245.

Bertrand, J.R.: Nouveaux terroirs en Galice méridionale. La Haute-Limia. En "Les mutations dans le milieu rural». Actes du Colloque de Géographie rurale en l'honneur de Pierre Brunet. Université de Caen, 1995, págs. 99-112.

BOUHIER, A.: La Galice. Essai gégraphique d'analyse et d'interpretation d'un vieux complexe agraire. La Roche-sur-Yon, 1979,2 tomes, 756 et 760 p., 2 étuis de fig. et cartes horstexte.

BOUHIER, A.: La conversión de la Galice à l'élevage bovin laitier. En “Campagnes françaises et ibériques de l'Atlantique». Recherches rurales n. ${ }^{\circ}$ 2, 1998. GEASO-CERVIN. Bordeaux 3, págs. 5-34.

BOUHIER, A.: Lourdeurs du passé et mutations recéntes: la situation actuelle de l'agriculfure galicienne (1965-1996). En «Annales de Géographie", n. 599 , janvier-février 1998, págs. 3358.

BRUNET, P.: La perception du paysage rural par notre société. Cahiers Royal Académie Agricole Française, n. ${ }^{\circ} 4,1996$, págs. 148-150.

Conselleria de Agricultura, Ganderia e Politica Agroalimentaria. Dirección Xeral de Desenvolvemento rural. Xunta de Galicia, 1999. Estadisticas de Concentración Parcelaria.

FERnÁNDEZ, G.: La economía agraria gallega en 1996. Ed. Dagur, Madrid, pág. 297.

FERNANDEZ, G.: La economía agraria gallega en 1997. Ed. F.G. Estudios Económicos y Sociales. Madrid, 1998, pág. 339.

FALTRĖS, P.: L'arc atlantique: un concept nouveau dans l'aménagemet européen. En "Homes et Terres du Nord", n. ${ }^{\circ}$ 2-3. 1991, págs. 147-151.

Faltrès, P.: Pour une delimitation de l'Europe atlantique, En «Paysages et Sociétés". Mélanges Géographiques en l'honneur du Professeur Abel Bohier. Université de Poitiers, 1990, págs. 7-14.

Floristan, A. y Lizarraga, M.A.: Cambios en los paisajes rurales del Pirineo occidental español. En "Paysages et Socitétés". Mélanges Géographiques en l'honneur du Professeur Abel Bouhier. Université de Poitiers, 1990, págs. 239-250.

Floristan, A. y TORRES, M.P.: Influencias pastoriles en el paisaje rural del Valle de Baztán. Rev. Pirineos, n. ${ }^{\circ}$ 95. Jaca, 1970, págs. 5-46.

Franco Aliaga, T.: Las actividades agrarias en España. Ed. U.N.E.D. Madrid, 1998, pág. 205. Galicia en cifras. Xunta de Galicia. Varias fechas de las que la última ha sido 1997. 
Garcia Fernandez, J.: Los paisajes agrarios de la España atlántica. Departamento de Geografía. Universidad de Valladolid, 1974. 387 páginas mecanografiadas.

LABASSE, J.: L'Europe des régions. Ed. Flammarion, 1991, pág. 432.

Mensua Fernandez, S.: La originalidad geográfica de Galicia y sus problemas. En «Estudios agrobiológicos de la provincia de La Coruña». Instituto de Investigaciones Geológicas, Edafológicas y Agrobiológicas de Galicia. Santiago de Compostela, 1996, págs. 17-32.

MoRALES, Gil, A.: Aspectos geográficos de la horticultura de ciclo manipulado en España. Ed. Universidad de Alicante, 1997, pág. 167.

NAYLON, J.: Core and periphery in the European Union. On the periphery. A view from rural Galicia. Leeds Paper on Spain in Europe. T.M. Cooper, 1996, págs. 39-79.

Poussard, A.: L'Arc Atlantique. Chronique d'une coopération interrégionale. Presses Universitaires de Rennes. Rennes, 1997, pág. 241.

TORRES LUNA, M.P. de: Ensayo de tipificación de los paisajes rurales gallegos. Rev. Geographica, n. ${ }^{\circ} 2$, abril-junio, 1972, págs. 3-23.

TORRES LUNA, M.P. de: La agricultura de montaña en Galicia. Una visión geográfica. En "Medio siglo de cambios agrarios en España (1940-1990)". Ed. Diputación Provincial de Alicante. Alicante, 1993, págs. 805-836.

TORRES LuNA, M.P. de: La Navarra húmeda del Noroeste. Estudio geográfico de la ganadería. C.S.I.C. Madrid, 1971 , pág. 178.

Torres LunA, M.P. DE: Los caminos de Santiago y la Geografía de Galicia. Rutas, paisajes, co-

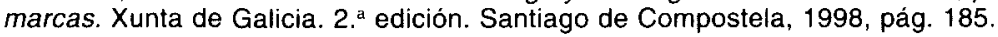

TORRES LUNA, M.P. DE: Santa Comba. Aspectos geográficos de un municipio gallego. Aula Parroquial de Cultura. Santa Comba, 1997, págs. 36-63.

TORRES LUNA, M.P. DE: Transformations démographiques et agraires récentes dans les montagnes de Galice (Espagne). En "Moyennes montagnes européennes. Nouvelles fonctions, nouvelles gestions de l'espace rural". $1^{\text {eres }}$ Journées Internationales. Actes du Colloque de Clermont-Ferrand, mai 1998. Université Blaise Pascal. Clermont-Ferrand, 1999, págs. $203-$ 224.

TorRes Luna, M.P. DE, Bertrand, J.R., et al.: Déprise agricole en Galice. Rev. Norois, $n{ }^{\circ} 158$, 1993, Poitiers, t. 40, págs. 217-233.

TORRES LUNA, M.P. DE et al.: Galicia, rexión de contrastes xeográficos. Universidade de Santiago de Compostela. Serie Galicia, $n{ }^{\circ}$ 2. Santiago, reimpresión de 1998, pág. 210.

TORRES LUNA, M.P. DE et al.: Le vignoble: un type d'exploitation agraire individualisé en Galice. En «Hommage à Alain Huetz de Lemps". Collection Maison des Pays Ibériques, $n .^{\circ} 66$. Press Universitaires de Bordeaux-CERVIN, 1996, págs. 449-460.

TORRES LUNA, M.P. DE et al.: Parroquias y arciprestazgos de Galicia. Universidade de Santiago de Compostela, 1994, pág. 371 y 8 mapas fuera de texto.

TORRES LUNA, M.P. DE et al.: Transformations récentes des espaces ruraux galiciennes. En "Campagnes françaises et ibériques de l'Atlantique". Recherches rurales n. ${ }^{\circ} 2,1998$. GEASO-CERVIN. Bordeaux 3, págs. 19-34.

VV.AA.: Le développement régional rural en Europe. Ed. Centre de Publications de l'Université de Caen, 1991, pág. 121. 